\title{
Erratum to: Self-rated health and life satisfaction among Canadian adults: associations of perceived weight status versus BMI
}

\author{
Katya M. Herman • Wilma M. Hopman •
}

Mark W. Rosenberg

Published online: 17 April 2013

(C) Springer Science+Business Media Dordrecht 2013

\section{Erratum to: Qual Life Res}

DOI 10.1007/s11136-013-0394-9

Figure 3 in the original publication was a duplicate of Fig. 2. The correct Fig. 3 is shown below.

The online version of the original article can be found under doi:10.1007/s11136-013-0394-9.

\section{K. M. Herman}

School of Kinesiology and Health Studies, Queen's University,

Kingston, ON, Canada

\section{K. M. Herman $(\bowtie)$}

Department of Kinesiology and Physical Education, McGill

University, 475 Pine Avenue West, Montreal, QC H2W 1S4,

Canada

e-mail: katya.herman@mcgill.ca

W. M. Hopman

Clinical Research Centre, Kingston General Hospital,

Queen's University, Kingston, ON, Canada

W. M. Hopman · M. W. Rosenberg

Department of Community Health and Epidemiology,

Queen's University, Kingston, ON, Canada

M. W. Rosenberg

Department of Geography, Queen's University, Kingston,

ON, Canada 

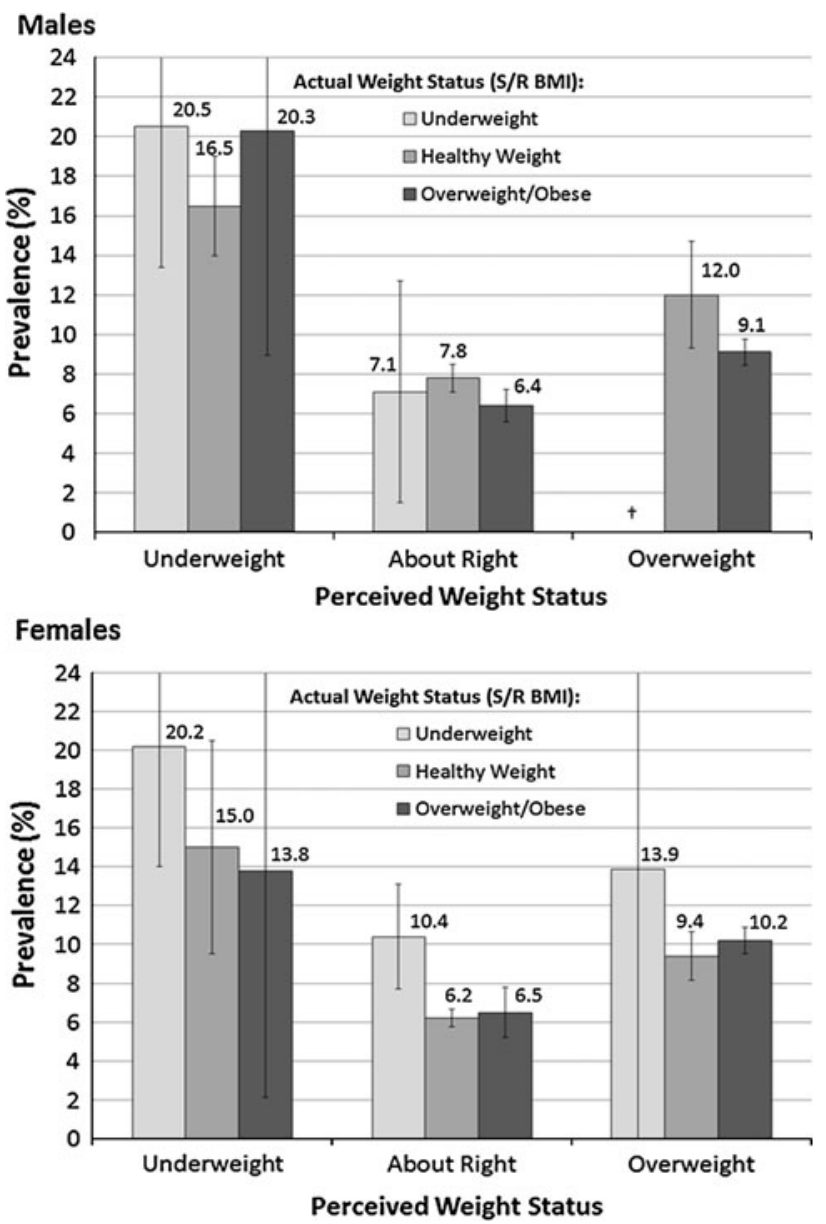

Fig. 3 Prevalence of being less than satisfied with life in adults aged 18-65 years, by perceived weight status and self-reported BMICanadian Community Health Survey Cycle 3.1 (2005). ${ }^{\dagger}$ Unweighted $\mathrm{n}$ did not meet minimum required by Statistics Canada for data release 